\title{
Preparation and Analyses of the Multifunctional Properties of 2D and 3D MOFs Constructed from Copper(I) Halides and Hexamethylenetetramine
}

\author{
Xiuying Qiao, Yafang Ge, Yuanyuan $\mathrm{Li}$, Yunyin $\mathrm{Niu}, * \odot$ and Benlai $\mathrm{Wu}^{\odot}$ \\ College of Chemistry and Molecular Engineering, Zhengzhou University, Henan 450001, P. R. China
}

Supporting Information

ABSTRACT: In this article, two two-dimensional and three-dimensional metal-organic frameworks are synthesized by the self-assembly of copper(I) halide and the hexamethylenetetramine ( $\mathrm{hmt}$ ) ligand. Compound $\mathbf{1}$ is a twodimensional metal-organic framework composed of a pyramidal $\mathrm{Cu}_{4} \mathrm{I}_{5}$ cluster and hexamethylenetetramine, in which hmt-bridged $\mathrm{Cu}$ clusters form a twodimensional $(4,4)$-connected net with a point symbol of $\left(4^{4} \cdot 6^{2}\right)\left(4^{4} \cdot 6^{2}\right)$. Compound 2 is a homochiral three-dimensional metal-organic framework material generated through an unusual spontaneous crystallization from achiral precursors. The two compounds were characterized by a series of analyses such as infrared spectroscopy, elemental analysis, circular dichroism spectroscopy, and powder X-ray diffraction. Both of them exhibit unexpected stability under a wide range of conditions of acid and base. In addition, the fluorescence intensity changes regularly under acid-base conditions. Stokes

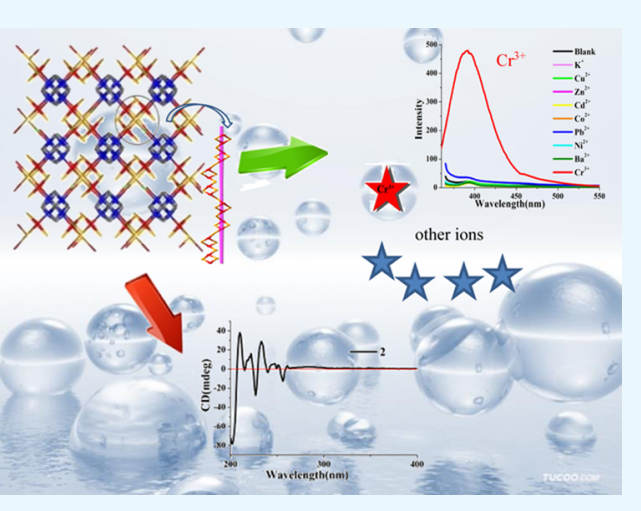
shift shows a good linear relationship with $-\log \left[\mathrm{H}^{+}\right]$, which makes them become promising acid-base sensors. Compounds 1 and 2 also display selective adsorption and a significant degradation effect on the organic dye methylene blue. In addition, the fluorescence study indicated that compound 2 could be used as a sensor to detect $\mathrm{Cr}^{3+}$.

\section{INTRODUCTION}

At present, the assembly of metal-organic frameworks is of great significance because of their high specific surface area, porosity, and plasticity, together with structural diversity and interesting topologies. In some aspects of chirality, gas storage, catalysis, zeolite behavior, etc., they show potential applications as functional materials. ${ }^{1-4}$ One of the basic strategies for the construction of functional materials is the employment of organic ligands with tetrahedral nodes. Since the hexamethylenetetramine (hmt, by name urotropine) molecule contains four tetrahedral nitrogen atoms after coordination, it becomes a potential multifunctional tetrahedral node. The crystal structures of copper chloride and hmt have been obtained, but the desired crystal structure has not been obtained with copper(I) bromide and iodide as inorganic building centers. This article helps overcome this challenge. ${ }^{5}$ From 1923, the molecular structure of hmt began to enter our field of vision. ${ }^{6,7}$ Due to the fascinating structure of cage trialkylamine, there has been great interest in the fields of organic synthesis, chemical industry, molecular catalysis, disinfectants, pesticides, curing agents, pharmaceutical physics, and military applications. ${ }^{8} \mathrm{Hmt}$ exhibits a variety of coordination modes including monodentate $(t-)$, bidentate $\left(\mu_{-}\right)$, tridentate $\left(\mu_{3^{-}}\right)$, and tetradentate $\left(\mu_{4^{-}}\right)$ligands in combination with metal salts and produces a large number of fascinating functional metal-hmt complexes. ${ }^{9}$ It is worth mentioning that there exist coordinatively unsaturated sites (refers to nitrogen) for the first three coordination configurations $\left(t-, \mu-, \mu_{3}-\right)$, which may have laid the foundation for ion recognition. However, it is very difficult to achieve pure chirality from the achiral precursor hmt. The addition of an inducer has paved the way to a new field in the development of pure chiral materials. ${ }^{10}$ Due to the relative earth abundance of these metals, the participation of copper species can form functional mononuclear or multinuclear metal-cluster complexes. This has led to an interest in the development and utilization of copper metal salts. ${ }^{11-18}$

In this paper, $\left\{[\mathrm{hmt}]\left[\mathrm{Cu}_{4} \mathrm{I}_{5}\right]\left[\mathrm{H}_{2} \mathrm{O}\right]_{5}\left[\mathrm{NH}_{4}\right]^{+}\right\}_{n}(\mathbf{1})$ and $\left\{[\mathrm{hmt}]\left[\mathrm{Cu}_{3} \mathrm{Br}_{3}\right]\left[\mathrm{H}_{2} \mathrm{O}\right]\right\}_{n}(2)$ were synthesized. The formed $\mathrm{Cu}_{4} \mathrm{I}_{5}$ cluster is connected to four $\mathrm{N}$ atoms on hmt. It turns out that multifunctional materials may be produced by clusters instead of metal centers. ${ }^{19}$ Since the copper iodide clusters form $\mathrm{Cu}_{4} \mathrm{I}_{4}$ (or $\mathrm{Cu}_{3} \mathrm{I}_{4}$ ) as four-connected nodes, ${ }^{20}$ the clusters are diverse in form and complicated in structure. The formation of $\mathrm{Cu}_{4} \mathrm{I}_{5}$ clusters in this paper may give the material unique functionality. Further, copper(I) bromide forms a three-coordinate structure with hexamethylenetetramine to form a three-dimensional structure. It was also synthesized for the first time.

Our team has long been committed to the construction of organic-inorganic hybrid compounds and the analysis of their

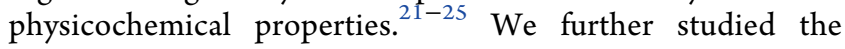

Received: May 10, 2019

Accepted: July 9, 2019

Published: July 19, 2019 


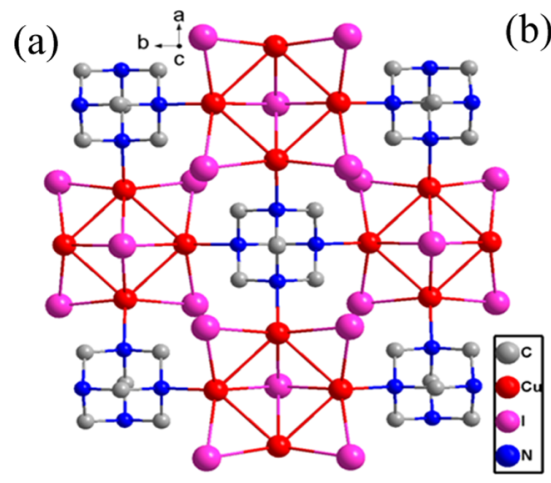

(b)

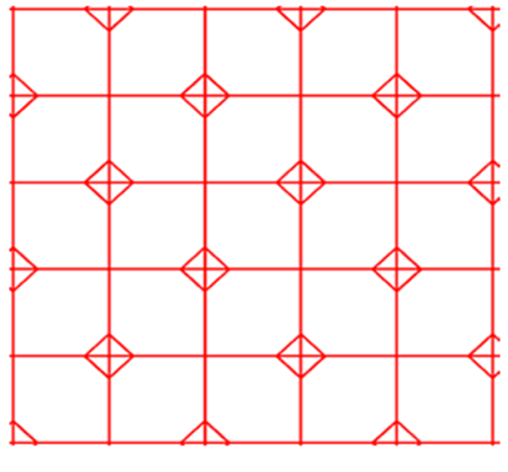

(c)

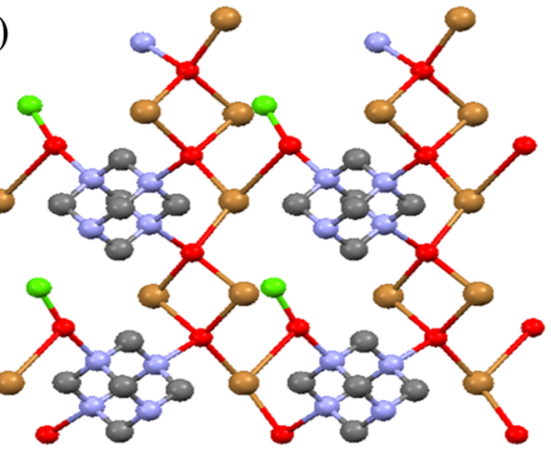

(d)

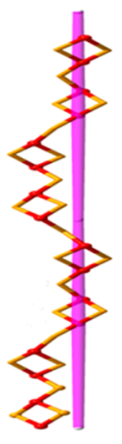

Figure 1. (a) Coordination environment of compound 1 (hydrogen atoms have been omitted for clarity). (b) Topological structure of the $2 \mathrm{D}$ network in 1. (c) Stacked view from the $a$-axis direction. (d) Single-stranded right-handed helical strand twisted along the $b$-axis.

properties of the compounds and found that they have high stability under acid-base conditions. The detection of acidbase stability to organometallic compounds was common, ${ }^{26-29}$ but there are few examples of this in the field of organicinorganic hybrid compounds, mainly because of their instability under acidic or basic conditions. ${ }^{30}$ Further, compounds 1 and $\mathbf{2}$ have been found to have good photocatalytic degradation properties for the organic dye methylene blue. Since trivalent metal ions play an important role in the human body and in the environment, we chose $\mathrm{Cr}^{3+}$ to evaluate the characteristics of fluorescent probes and found that compound 2 exhibited a high-sensitivity and highselectivity fluorescence response to $\mathrm{Cr}^{3+}$. It is known that due to complexation with metal ions, charge-transfer interaction is reduced to enhance the fluorescence signal. ${ }^{31}$ We conclude that the availability of lone-pair electrons on the uncoordinated nitrogen of compound $\mathbf{2}$ without coordination will promote the complexation with metal ions.

\section{RESULTS AND DISCUSSION}

Description of Crystal Structures. Compound 1 indicates that $\left\{[\mathrm{hmt}]\left[\mathrm{Cu}_{4} \mathrm{I}_{5}\right]^{-}\left[\mathrm{H}_{2} \mathrm{O}\right]_{5}\left[\mathrm{NH}_{4}\right]^{+}\right\}_{n}(\mathbf{1})$ crystallizes in a tetragonal space group $P 4 / \mathrm{nmm}$. The asymmetric unit of the compound contains one hmt ligand and $\left[\mathrm{Cu}_{4} \mathrm{I}_{5}\right]^{-}$clusters, as shown in Figure S1a. Interestingly, the geometry of the anionic $\left[\mathrm{Cu}_{4} \mathrm{I}_{5}\right]^{-}$cluster is a square pyramid with four $\mathrm{Cu}$ and five I atoms (Figure S1b). The compound is formed by the $\left[\mathrm{Cu}_{4} \mathrm{I}_{5}\right]^{-}$clusters and the ligand $\mathrm{hmt}$. In compound $\mathbf{1}$, the hmt ligand is tetradentate $\left(\mu_{4}-\mathrm{hmt}\right)$, linking to four metal ions (Figure 1a). Two hmt molecules form a 10-membered ring with two $\left[\mathrm{Cu}_{4} \mathrm{I}_{5}\right]^{-}$clusters. The distance between $\mathrm{Cu} \cdots \mathrm{Cu}$ in the 10 -membered ring is $6.584 \AA$ and between $\mathrm{C} \cdots \mathrm{C}$ is $3.529 \AA$ (Figure S1c). In view of the topology, however, the minimum closed loops around the nodes involved in symmetry-related ligands and $\mathrm{Cu} 1$ ions are $\left(4^{4} \cdot 6^{2}\right)$. Thus, the two-dimensional (2D) structure of compound 1 can be described as an interesting four-connected net with the point symbol of $\left(4^{4} \cdot 6^{2}\right)$ $\left(4^{4} \cdot 6^{2}\right)$ in which $\mathrm{Cu}(\mathrm{I})$ centers and ligands act as fourconnected nodes (Figure $1 \mathrm{~b}$ ).

The compound $\left\{[\mathrm{hmt}]\left[\mathrm{Cu}_{3} \mathrm{Br}_{3}\right]\left[\mathrm{H}_{2} \mathrm{O}\right]\right\}_{n}$ (2) crystallizes in the chiral space group $\mathrm{P}_{3}$ with a Flack parameter of $0.09(12)$. Single-crystal X-ray analysis reveals that 2 represents a rare three-connected three-dimensional chiral network. The structural unit of $\mathbf{2}$ is shown in Figure S2a. In compound 2, the hmt ligand is tridentate $\left(\mu_{3}-\mathrm{hmt}\right)$, linking to three metal ions (Figure 1c). There are three different coordination environments for $\mathrm{Cu}$ atoms in the structural unit diagram. The $\mathrm{Cu}$, $\mathrm{Cu} 2$, and $\mathrm{Cu} 3$ atoms are all coordinated by the $\mathrm{N}$ atom from the hmt ligand. $\mathrm{Cu} 1$ and $\mathrm{Cu} 2$ ions are interconnected by two $\mu_{2}-\mathrm{Br} 1$ and $\mu_{2}-\mathrm{Br} 2$, respectively, to form a dinuclear $\mathrm{Cu}$ cluster. From the $b$-axis direction, a distorted quadrangle is formed (Figure S2b). The distorted quadrilateral consists of two hmt ligands and a small quadrilateral formed by two copper atoms and two bromine atoms. The distance between $\mathrm{Cu} \cdots \mathrm{Cu}$ in the quadrangle is $10.857 \AA$. From the $a$-axis direction, units of compound $\mathbf{2}$ are arranged in parallel to each other in the $A B A B$ manner to produce a chiral structure (Figure 1c). It forms right-handed helixes along the $b$ axis with large pitches of 27.2948(55) A. The ligand and metal ion $\mathrm{Cu}(\mathrm{I})$ assembly yields a crystal helical chirality (Figure 1d). Synthesis of a homochiral network that can be established by three methods has been reported: (i) using enantiopure precursors, (ii) through spontaneous resolution occurring during crystallization, and (iii) using achiral precursors in the presence of chirality-inducing agents such as chiral additives, chiral solvents, or chiral catalysts. ${ }^{41 \mathrm{c}}$ The chiral compound 2 in this paper is synthesized by self-assembly and crystallization in 

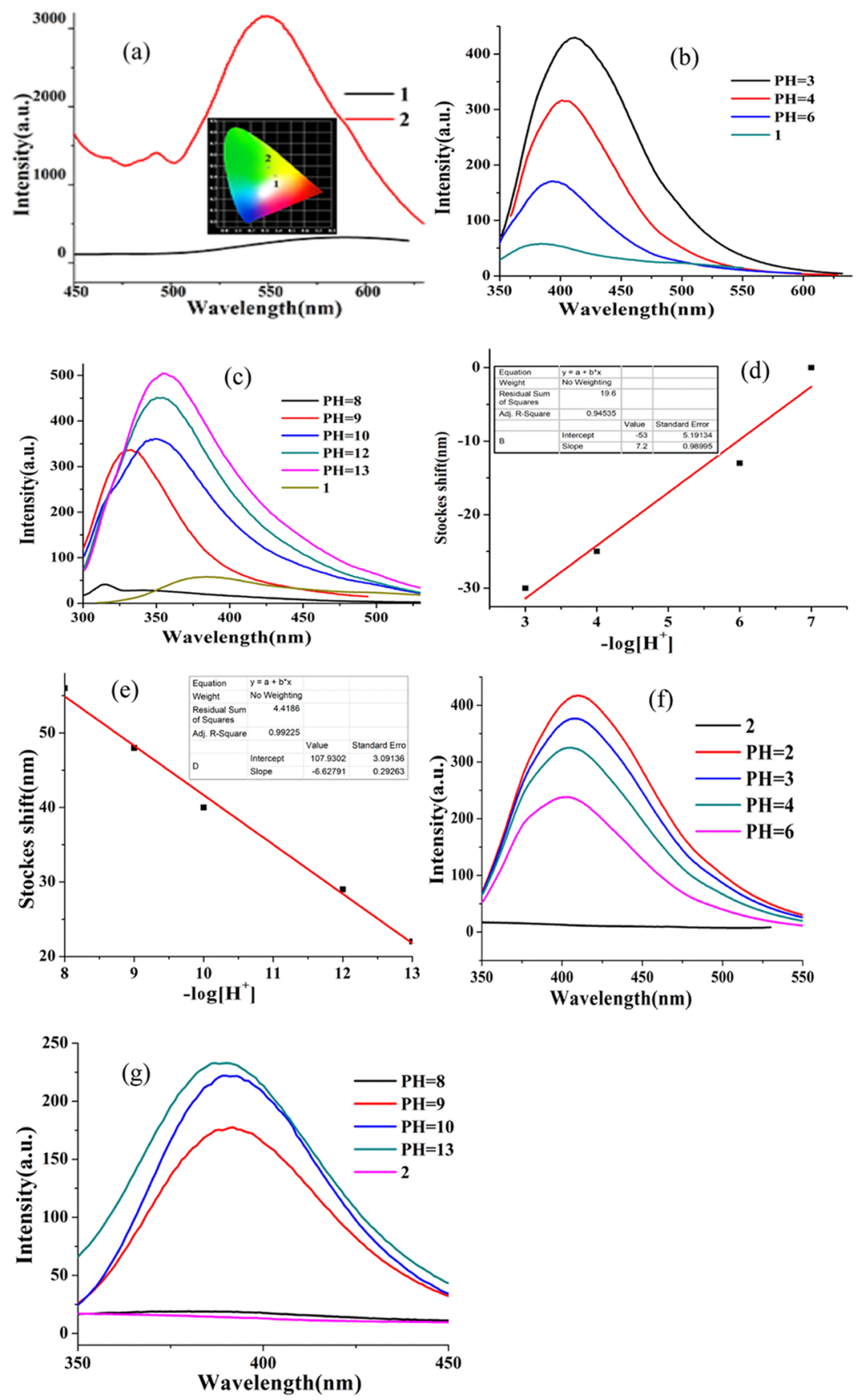

Figure 2. (a) Emission spectra of compounds $\mathbf{1}$ and $\mathbf{2}$ in the solid state at room temperature. (b) Fluorescence analysis of compound $\mathbf{1}$ in the $\mathrm{pH}$ range of 3-6 was processed. (c) Fluorescence analysis of compound 1 in the $\mathrm{pH}$ range of 8-13 was processed. (d) Linear relationship between the Stokes shift at $\mathrm{pH}=3-6$ and the $-\log [\mathrm{H}]$ value of the solution. (e) Linear relationship between the Stokes shift at $\mathrm{pH}=8-13$ and the $-\log \left[\mathrm{H}^{+}\right]$ value of the solution. (f) Fluorescence analysis of compound $\mathbf{2}$ in the $\mathrm{pH}$ range of 2-6 was processed. (g) Fluorescence analysis of compound 2 in the $\mathrm{pH}$ range of $8-13$ was processed.

solution using $\mathrm{CuBr}$ and an organic ligand (hmt), which should be assigned to method (ii).

Acid-Base Resistance. We soaked compounds 1-2 in an aqueous solution of acid and base to explore their stability to acid and base. Compounds $\mathbf{1 - 2}$ of the same quality were soaked for 1 day at a range of $\mathrm{pH}$ values and then subjected to IR spectroscopy measurements. Compound $\mathbf{1}$ can maintain its structure at $\mathrm{pH}=3-13$. In the infrared spectrum, the stretching vibration peak of the $\mathrm{C}-\mathrm{N}$ group at about 1366 $\mathrm{cm}^{-1}$ gradually disappears, indicating that the acid concentration changes, which causes the skeleton to collapse. There is no peak at $\mathrm{pH}=1$ and $\mathrm{pH}=2$ at $3257 \mathrm{~cm}^{-1}$ (Figure S3a). However, for compound 2, at $\mathrm{pH}=1$, there is no peak at 3257 $\mathrm{cm}^{-1}$. This indicates that compound 2 can remain structurally intact in the range of $\mathrm{pH}=2-13$ (Figure S3b).

Photoluminescence Properties. The solid-state fluorescence properties of compounds $\mathbf{1 - 2}$ at normal temperature were studied, and the fluorescence intensity of compound $\mathbf{1}$ was weaker than that of compound 2 . The corresponding luminescent color of compound $\mathbf{1}$ is yellow and that of compound $\mathbf{2}$ is green as shown by $\operatorname{CIE}(x, y)$ (Figure 2a). The emission wavelength of the compounds shifts; we further 

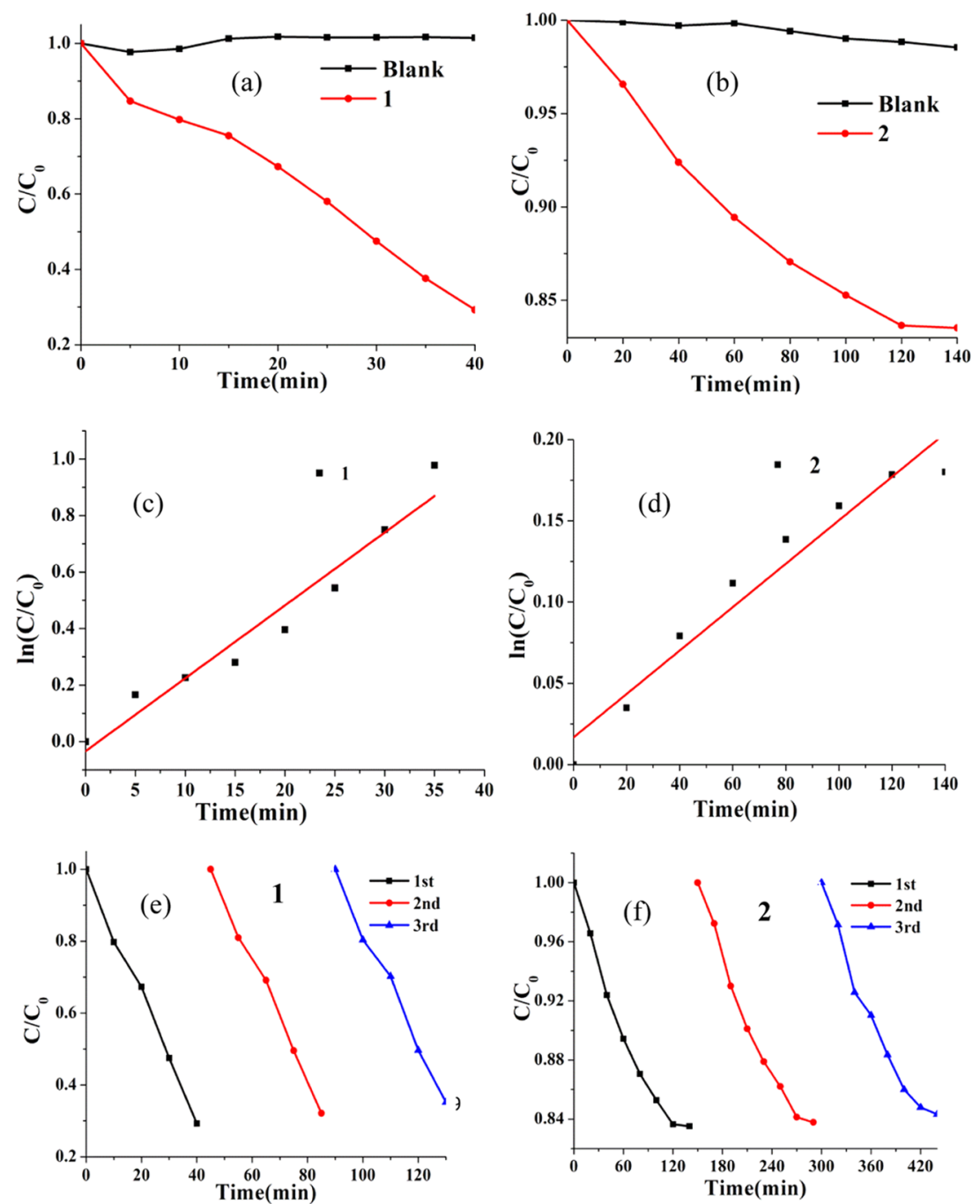

Figure 3. (a) Compound 1 and blank photocatalytic degradation of MB dye. (b) Compound 2 and blank photocatalytic degradation of MB dye. (c) Photocatalytic reaction kinetics of compound 1. (d) Photocatalytic reaction kinetics of compound 2. (e) Recycling test with compounds 1 and 2 (f) for MB photodegradation.

speculate that the emission of the compound may be caused by a different halide-metal charge transfer. In view of the intensity of fluorescence, we monitored the solvent fluorescence changes of compounds at different $\mathrm{pH}$ values. ${ }^{32}$ The $\mathrm{pH}$ is adjusted herein using an aqueous solution of hydrochloric acid and sodium hydroxide to record the corresponding fluorescent emissions. The emission wavelength of compound 1 in an aqueous solution was $383 \mathrm{~nm}\left(\lambda_{\mathrm{ex}}=290\right.$ $\mathrm{nm})$. As the $\mathrm{pH}$ gradually reached $\mathrm{pH}=3$, the maximum emission wavelength was $412 \mathrm{~nm}$. Throughout the experiment, the total Stokes shift reached $20 \mathrm{~nm}$ (Figure $2 \mathrm{~b}$ ). In addition, the Stokes shift showed an overall blue shift, after adding the base. However, as the $\mathrm{pH}$ increases (Figure 2c), the changes in compound 1 are as follows: $\mathrm{pH}=8(314 \mathrm{~nm})<\mathrm{pH}=9(332$ $\mathrm{nm})<\mathrm{pH}=10(348 \mathrm{~nm})<\mathrm{pH}=12(353 \mathrm{~nm})<\mathrm{pH}=13$ $(355 \mathrm{~nm})$. In addition, the results show that the Stokes shift has a linear relationship with $-\log \left[\mathrm{H}^{+}\right]$(Figure 2d,e). Compound 2 gradually decreases in fluorescence intensity with increasing $\mathrm{pH}$ in an acidic aqueous solution (Figure $2 \mathrm{f}$ ). As the $\mathrm{pH}$ in the alkaline aqueous solution increases, the fluorescence intensity of compound $\mathbf{2}$ is gradually enhanced (Figure $2 \mathrm{~g}$ ). The reason for the change in fluorescence intensity under different acid-base conditions is that when a certain group in the compounds is protonated or deprotonated, it is possible to induce a change in the fluorescence intensity of the compounds. The electrons of the electron donor are transferred to the electron acceptor, which produces a fluorescence-quenching phenomenon. When the electron donor is combined with the proton, the electron transfer is inhibited, thereby causing the recovery of fluorescence. ${ }^{32 c}$

Dye Adsorption. Organic dyes are used in many fields. ${ }^{33-35}$ Therefore, a method for extracting dyes from a solution has been of wide concern. ${ }^{36-38}$ The absorption of dye molecules by the use of organometallic compounds is very popular. Methylene blue (MB) is used herein as the adsorbed dye. Compared with compound 2, compound $\mathbf{1}$ has a more obvious adsorption effect at $210 \mathrm{~min}$ (Figures S5 and S6). The amount of adsorbed dye can be calculated by the following formula: $Q_{\mathrm{eq}}=\left(C_{0}-C_{\mathrm{eq}}\right) V / M{ }^{39}$ It is known from the figure that the adsorption effect of compound $\mathbf{2}$ is weaker than that of compound 1 (Figure S7), and the adsorption amount of compound $\mathbf{2}$ is also increased by prolonging the adsorption time. Therefore, both compounds 1 and $\mathbf{2}$ have a good adsorption capacity for the organic dye MB.

Photocatalytic Activities. The UV-vis diffuse reflectance spectra of a powder sample with a band gap $\left(E_{\mathrm{g}}\right)$ of $\mathbf{1}$ is used, 
which is reflected using reflectance. The Kubelka-Munk function $F$ is plotted on the energy map $E$, and $F=(1-R)^{2} /$ $2 R$ is converted from the recorded diffuse reflection data. ${ }^{40}$ The gap values are 1.55 and $1.87 \mathrm{ev}$, as shown in Figure S8. This indicates that compounds $\mathbf{1 - 2}$ are semiconducting when exposed to visible light and have possible photocatalytic activity. The photocatalysts (compounds 1-2) are semiconductor materials. Therefore, the organic dye $\mathrm{MB}$ was photodegraded by the photoexcitation of compounds 1-2. The degradation efficiency is mainly determined by the free carrier available on the surface of the photocatalysts. Semiconductor materials have been shown to have higher electron transport rates and better material properties. The photocatalytic degradation efficiencies of the organic dye MB with respect to compounds 1-2 are shown in Figures S9 and $\mathrm{S} 10$, and the absorption spectrum of $\mathrm{MB}$ is remarkably lowered as the reaction time increases. Furthermore, the change of the concentration of the MB solution with time was plotted $\left(C_{0}\right.$ : initial concentration of MB; $C$ : dye concentration at any given time). The results showed that the degradation rate of compound 1 in $40 \mathrm{~min}$ was $70 \%$, whereas the degradation rate of compound 2 in 140 min was 16\% (Figure 3a,b). Compound 1 has a high decomposition activity for MB under visible-light irradiation. We studied the reaction kinetics. The catalytic process conforms to the quasi-first-order kinetic equation as shown in Figure $3 \mathrm{c}$,d. Then, we tested the stability of compounds 1-2 before and after catalysis, and the characteristic peaks before and after the contrast infrared image basically existed (Figure S11). To evaluate the recoverability and reusability of compounds $\mathbf{1}$ and $\mathbf{2}$, photocatalytic degradation of $\mathrm{MB}$ for three cycles was performed. As can be seen from Figure $3 \mathrm{e}, \mathrm{f}$, similar photocatalytic efficiencies were maintained even after repetition. It can be seen from Figure S11c,d that the powder X-ray diffraction (PXRD) pattern of the compound after photodegradation is almost the same as that of the synthetic sample, which further proves that compounds $\mathbf{1}$ and $\mathbf{2}$ do not degrade under photodegradation conditions.

Circular Dichroism (CD). Since compound 2 has chiral space groups, solid-state circular dichroism (CD) spectra have been measured for further demonstrating its homochiral nature. ${ }^{41}$ The different peaks according to positive and negative Cotton effects appear in the range of $200-260 \mathrm{~nm}$, which are shown in the CD spectra of compound 2 (Figure 4) The CD spectrum of 2 exhibits positive Cotton effects centered at 210, 221, and $233 \mathrm{~nm}$ and negative Cotton effects centered at 202, 227, and $257 \mathrm{~nm}$. The results well-testify the chirality of compound 2.

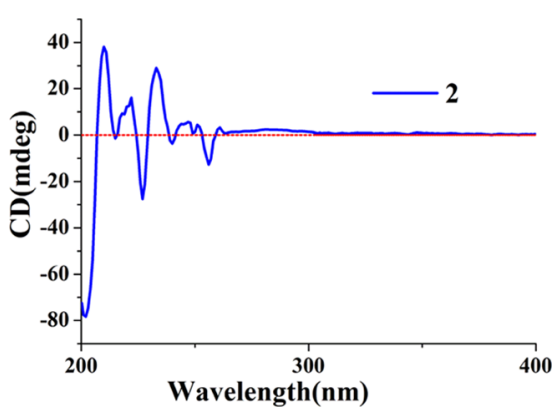

Figure 4. Solid-state CD spectra of compound 2.
Sensing of the Metal Cations. Therefore, we use the potential fluorescence properties of chiral compound to detect various metal ions such as $\mathrm{K}^{+}, \mathrm{Cu}^{2+}, \mathrm{Zn}^{2+}, \mathrm{Cd}^{2+}, \mathrm{Co}^{2+}, \mathrm{Pb}^{2+}$, $\mathrm{Ni}^{2+}, \mathrm{Ba}^{2+}, \mathrm{Cr}^{3+}$, and $\mathrm{Fe}^{3+}$. However, chiral compound recognition is a chiral match between a chiral host and an object, just like a hand and a glove. ${ }^{42}$ As shown in Figure 5a, it is observed that compound 2 has high sensitivity and specificity for the selectivity of $\mathrm{Cr}^{3+}$ ions in aqueous solution. Trivalent chromium $\left(\mathrm{Cr}^{3+}\right)$ plays an important role in the diet of humans and animals. It is also a stabilizer for nucleic acids, which can prevent cancer. The lack of trivalent chromium can cause diabetes, arteriosclerosis, and high blood pressure. Excessive intake can lead to genotoxic effects. In addition, how to use the convenient and quick method to detect trivalent chromium is an urgent problem to be solved, due to its diversification and participation in industrial and agricultural activities, making trivalent chromium an environmental pollutant. ${ }^{43}$ The fluorescence intensity at $392 \mathrm{~nm}$ was found to be enhanced. From the fluorescence intensity ratio of different metal ions in the aqueous solution, it is found that the intensity ratio on adding $\mathrm{Cr}^{3+}$ is 22 times that of the blank (Figure $5 b$ ). In contrast, other metal ions would have no obvious influence on the fluorescence intensity of compound 2 . The luminescence intensity gradually increases with the increase of $\mathrm{Cr}^{3+}$ ion concentration. The fluorescence intensity of compound 2 at $392 \mathrm{~nm}$ is proportional to the concentration of $\mathrm{Cr}^{3+}$ within a certain range. A linear relationship of $\mathrm{Cr}^{3+}$ detection under optimal conditions was obtained at $392 \mathrm{~nm}$ with a correlation coefficient of 0.996 (Figure S12). The increase in fluorescence intensity may be due to the formation of an extended electron conjugation system between metal ions, and it is also possible that the chelation of metal ions with compound 2 produces stiffness in the molecule. The regression equation is $Y=282.533+19.503 X$. According to the reported method, ${ }^{44,45}$ the limit of detection for $\mathrm{Cr}^{3+}$ is up to $0.227 \mu \mathrm{M}$. The relationship between the fluorescence intensity and mole fraction is shown in Figure S13. The results show that the emission intensity is close to the maximum when the mole fraction of $\left[\mathrm{Cr}^{3+}\right] /\left([2]+\left[\mathrm{Cr}^{3+}\right]\right)$ is about 0.5 , indicating a $1: 1$ binding stoichiometry between 2 and $\mathrm{Cr}^{3+}$. All of these results are consistent with the coordination configuration of the ligand $\mu_{3}$-hmt with a single active coordinate $\mathrm{N}$ site in compound 2 . A possible sensing mechanism of the fluorescence enhancement of compound $\mathbf{2}$ in the solvent media is proposed, wherein the solvated $\mathrm{Cr}^{3+}$ with a larger ion radius forms complexes with 2 as shown in Figure $6 .{ }^{45 a}$ The metal cation $\mathrm{Cr}^{3+}$ was bound to the lone pair on the uncoordinated amino group nitrogen of $\mu_{3}$-hmt. The interaction of the cation $\mathrm{Cr}^{3+}$ with the lone pair on the nitrogen atom in hmt results in an inhibition of the photoelectron transfer process, giving rise to the observed enhancement of fluorescence emission. ${ }^{45-d}$

Thermogravimetric (TG) Studies. The TG curves of compounds 1-2 are provided in Figure S14. The frameworks of compounds 1 and 2 were stable up to ca. 300 and $240{ }^{\circ} \mathrm{C}$, and so the overall thermal stability is high. The TG trace of compound 1 exhibits two main steps of weight loss, which correspond to the release of coordinate inorganic groups and decomposition of organic groups. The organic ligand of compounds 1-2 decompose, which causes a decrease of 250$300{ }^{\circ} \mathrm{C}$. The decomposition of inorganic substances mainly occurs at $600-800{ }^{\circ} \mathrm{C}$. Due to the difference in the coordination mode of the ligands, the stable temperatures of compounds 1 and $\mathbf{2}$ are quite different. It appears that 

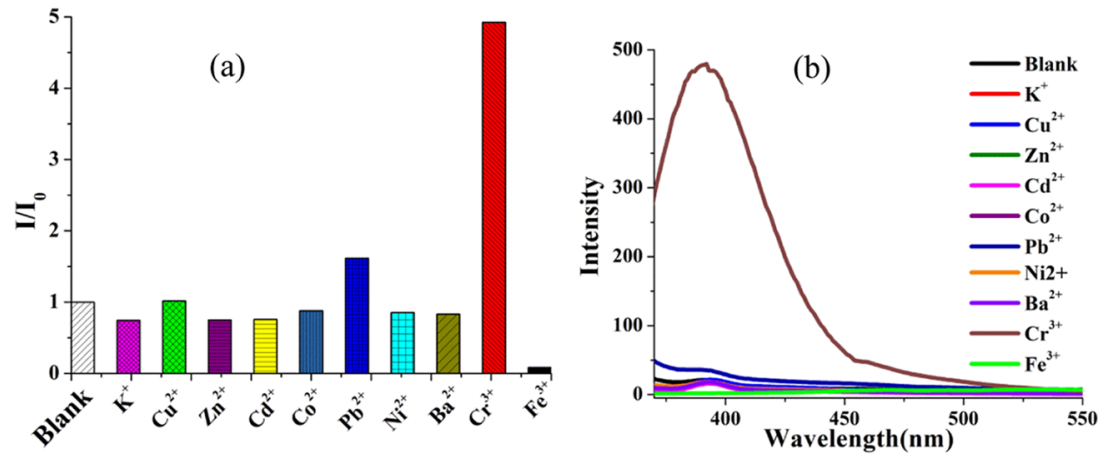

Figure 5. (a) Fluorescence intensity of compound 2 in aqueous solution with $1.0 \times 10^{-2} \mathrm{~mol} / \mathrm{L}$ metal ions $\left(\mathrm{K}^{+}, \mathrm{Cu}^{2+}, \mathrm{Zn}^{2+}, \mathrm{Cd}^{2+}, \mathrm{Co}^{2+}, \mathrm{Pb}^{2+}, \mathrm{Ni}^{2+}\right.$, $\mathrm{Ba}^{2+}, \mathrm{Cr}^{3+}$, and $\left.\mathrm{Fe}^{3+}\right) ; \lambda_{\mathrm{ex}}=345 \mathrm{~nm}$. (b) Fluorescence intensity ratio of different metal ions in aqueous solution ( $I$ and $I_{0}$ denote the fluorescence intensities of compound 2 with and without the metal ions of interest, respectively).

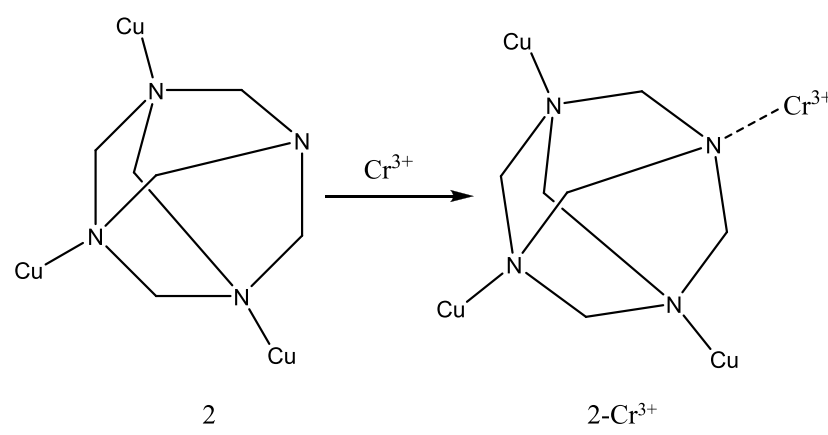

Figure 6. Possible sensing mechanism of compound 2 for the recognition of $\mathrm{Cr}^{3+}$.

compound 2 has only one mass drop and continuously loses weight from $300-800^{\circ} \mathrm{C}$, indicating that the decomposition of the ligand is completed in one step.

\section{CONCLUSIONS}

In summary, we produced two compounds by the selfassembly of copper(I) halides and a tetradentate hmt as a ligand. A two-dimensional metal-organic framework compound with $\mathrm{Cu}_{4} \mathrm{I}_{5}$ clusters was synthesized by reaction with $\mathrm{CuI}$, and it was reacted with $\mathrm{CuBr}$ to form a three-coordinate three-dimensional chiral structure. The study found that the compounds have good acid-base stability and the Stokes shift has a good linear relationship with $-\log \left[\mathrm{H}^{+}\right]$. In addition, we found that the compounds have the potential to adsorb and cause photocatalytic degradation of methylene blue by visible light. The highly selective and sensitive detection method of compound 2 for $\mathrm{Cr}^{3+}$ has been successfully applied to aqueous solutions.

\section{EXPERIMENTAL SECTION}

Synthesis of 1. Hexamethylenetetramine (hmt) (0.0014 g) was added to a stirred solution of colorless $\mathrm{CuI}(0.0019 \mathrm{~g})$ in $1.5 \mathrm{~mL}$ of dimethylformamide (DMF) and $1 \mathrm{~mL}$ of $\mathrm{NH}_{3} \mathrm{OH}$ in the presence of excess KI $(0.0066 \mathrm{~g})$. The resulting mixture was stirred for $5 \mathrm{~min}$ and filtered. The filtrate was allowed to stand and volatilized at room temperature to form pale-yellow crystals for about 3 months, and the collection rate was 20.05\%. IR ( $\left.\mathrm{KBr} \mathrm{cm} \mathrm{cm}^{-1}\right)$ : $3331(\mathrm{~m}), 2980(\mathrm{w}), 1599(\mathrm{w})$, 1448(w), 1623 (w), 1242 (s), 1215 (m), 1009 (s), 822(s), $701(\mathrm{~s})$. Elemental analysis for $\mathrm{C}_{6} \mathrm{H}_{26} \mathrm{Cu}_{4} \mathrm{I}_{5} \mathrm{~N}_{5} \mathrm{O}_{5}$ (\%): Calcd: $\mathrm{C}$, 6.34; H, 2.30; N, 6.16. Found: C, 6.38; H, 2.35; N, 6.21.
Synthesis of 2. Hexamethylenetetramine (hmt) $(0.0014 \mathrm{~g})$ was added to a stirred solution of colorless $\mathrm{CuBr}(0.0014 \mathrm{~g})$ in $1.5 \mathrm{~mL}$ of DMF and $1 \mathrm{~mL}$ of $\mathrm{NH}_{3} \mathrm{OH}$ in the presence of excess $\mathrm{KBr}(0.0048 \mathrm{~g})$. The resulting mixture was stirred for $5 \mathrm{~min}$ and filtered. The filtrate was allowed to stand and volatilized at room temperature to form pale-yellow crystals for about 3 months, and the collection rate was $35 \%$. IR $\left(\mathrm{KBr} \mathrm{cm}^{-1}\right): 3441$ (w), 3296 (s), 2888 (w), 1595 (s), 1457 (s), 1250 (s), 1028 (s), 991(s), 819 (s), 673(s). Elemental analysis for $\mathrm{C}_{6} \mathrm{H}_{14} \mathrm{Br}_{3} \mathrm{Cu}_{3} \mathrm{~N}_{4} \mathrm{O}$ (\%): Calcd: C, 12.24; $\mathrm{H}, 2.39 ; \mathrm{N}, 9.52$. Found: C, 12.20; H, 2.42; N, 9.56.

\section{ASSOCIATED CONTENT}

\section{S Supporting Information}

The Supporting Information is available free of charge on the ACS Publications website at DOI: 10.1021/acsomega.9b01356.

Important crystallographic data (Tables S1 and S2), crystal structures of compounds 1-2 (Figures S1 and S2), IR analysis of compounds $\mathbf{1 - 2}$ at different $\mathrm{pH}$ values (Figure S3), powder X-ray diffraction patterns of compounds 1-2 (Figure S4), adsorption of MB solution under UV light irradiation by the use of compounds 1-2 and the control experiment (blank) without any catalyst (Figures S5 and S6), MB adsorption capacity of compounds 1-2 (Figure S7), diffuse-reflectance UVVis-NIR spectra of $\mathrm{K}-\mathrm{M}$ functions vs energy $(\mathrm{eV})$ of compounds 1-2 (Figure S8), photocatalytic degradation of $\mathrm{MB}$ solution under UV light irradiation by the use of compounds $\mathbf{1 - 2}$ and the control experiment (blank) without any catalyst (Figures S9 and S10), catalytic infrared absorption spectrum before and after MB of compounds 1-2 and PXRD of different reaction stages of compounds 1-2 (Figure S11), fluorescent spectra of compound 2 (Figure S12), Job's plot of the complex formed by $\left[\mathrm{Cr}^{3+}\right] /\left([2]+\left[\mathrm{Cr}^{3+}\right]\right.$ ) (Figure S13), and TG plots of compounds $\mathbf{1 - 2}$ (Figure S14). CCDC reference numbers: 1898346 for $\mathbf{1}$ and 1898224 for $\mathbf{2}$ (PDF)

Crystallographic information file-1 (CIF)

Crystallographic information file-2 (CIF)

\section{AUTHOR INFORMATION}

\section{Corresponding Author}

*E-mail: niuyy@zzu.edu.cn. Tel.: +86 37167767627. 


\section{ORCID $\odot$}

Yunyin Niu: 0000-0002-9113-0438

Benlai Wu: 0000-0003-1354-3365

\section{Notes}

The authors declare no competing financial interest.

\section{ACKNOWLEDGMENTS}

Research efforts in Niu's group are supported by the National Science Foundation of China (No. 21671177).

\section{REFERENCES}

(1) Huang, J.; Ding, M.; Xu, Y.; Zeng, D.; Zhu, H.; Zang, D. M.; Bao, S. S.; Ma, Y. Q.; Zheng, L. M. Chiral expression from molecular to macroscopic level via $\mathrm{pH}$ modulation in terbium coordination polymers. Nat. Commun. 2017, 8, No. 2131.

(2) Hollyday, B. J.; Mirkin, C. A. Strategies for the Construction of Supramolecular Compounds through Coordination Chemistry. Angew. Chem., Int. Ed. 2001, 40, 2022-2043.

(3) Wu, Y. Y.; Xiong, L.; Jia, F.; Chen, L. $\mathrm{Cs}_{2} \mathrm{Ge}_{3} \mathrm{In}_{6} \mathrm{Se}_{14}$ : A Structure Transformation Driven by the Size Preference and Its Properties. Inorg. Chem. 2018, 57, 4667-4672.

(4) (a) Xuan, Y.; Wu, W.; Li, S. J. Synthesis and crystallographic characterization of a six coordinate $\mathrm{Cu}$ (II) complex based on hexamethylenetetramine ligand. Cryst. Res. Technol. 2009, 44, 127130. (b) Liu, C. F.; Zhao, N.; Zou, X. Q.; Zhu, G. S. Synthesis of an ultra-stable metal-organic framework for proton conduction. CrystEngComm 2018, 20, 3158-3161.

(5) Hu, L. X.; Wang, F.; Kang, Y.; Zhang, J. Structural Design of Zeolitic Cluster Organic Frameworks from Hexamethylentetramine and Copper-Halide Clusters. Cryst. Growth Des. 2016, 16, 71397144.

(6) Dickinson, R. G.; Raymond, A. L. The crystal structure of hexamethylene-tetramine. J. Am. Chem. Soc. 1923, 45, 22.

(7) Wyckoff, R. G. W.; Corey, R. B. Spectrometric measurements on hexamethylene-tetramine and urea. Z. Kristallogr. 1934, 89, 462.

(8) Conn, M. M.; Rebek, J. J. Self-Assembling Capsules. Chem. Rev. 1997, 97, 1647-1668.

(9) (a) Qian, J.; Hu, J. C.; Yoshikawa, H.; Zhang, J. F.; Awaga, K.; Zhang, C. A Three-Dimensional Hetero-Bimetallic Coordination Polymer with Unusual $(4,5)$-Connected Topology and Ferrimagnetic Property Based on Octacyanotungstate and Polydentate Ligand. Cryst. Growth Des. 2014, 14, 2288-2295. (b) Deng, Z. P.; Huo, L. H.; Xu, H.; Zhao, H.; Ng, S. W.; Gao, S. The first metal-organic framework containing an unprecedented in situ-generated C-substituted hexamethylenetetramine ligand. Dalton Trans. 2011, 40, 1224-1226.

(10) He, X.; Fang, K.; Guo, X. H.; Han, J.; Lu, X. P.; Li, M. X. A homochiral $\mathrm{Cu}(\mathrm{I})$ coordination polymer based on achiral precursors and its photocatalytic properties. Dalton Trans. 2015, 44, 1354513549 .

(11) Solomon, E. I.; Sundaram, U. M.; Machonkin, T. E. Multicopper Oxidases and Oxygenases. Chem. Rev. 1996, 96, 25632606.

(12) Klinman, J. P. Mechanisms Whereby Mononuclear Copper Proteins Functionalize Organic Substrates. Chem. Rev. 1996, 96, $2541-2562$.

(13) Koval, I. A.; Gamez, P.; Belle, C.; Selmeczi, K.; Reedijk, J. Synthetic models of the active site of catechol oxidase: mechanistic studies. J. Chem. Soc. Rev. 2006, 35, 814-840.

(14) Maheswari, P. U.; Roy, S.; Dulk, H.; Barends, S.; Wezel, G.; Kozlevcar, B.; Gamez, P.; Reedijk, J. The Square-Planar Cytotoxic $\left[\mathrm{Cu}^{\text {II }}\right.$ (pyrimol)Cl] Complex Acts as an Efficient DNA Cleaver without Reductant. J. Am. Chem. Soc. 2006, 128, 710-711.

(15) Koval, I.; Pursche, D.; Stassen, A.; Gamez, P.; Krebs, B.; Reedijk, J. The Dicopper(II) Complex of the Novel Asymmetric Dinucleating Ligand Hpy3asym as a Structural Model of Catechol Oxidase. Eur. J. Inorg. Chem. 2003, 2003, 1669-1674.
(16) Elsevier, C. J.; Reedijk, J.; Walton, P. H.; Ward, M. D. Ligand design in coordination chemistry: approaches to new catalysts, new materials, and a more sustainable environment. Dalton Trans. 2003, $10,1869-1880$

(17) Wanke, R.; Smoleński, P.; da Silva, M. F. C. G.; Martins, L. M. D. R.; Pombeiro, S. A. J. L. Cu(I) Complexes Bearing the New Sterically Demanding and Coordination Flexible Tris(3-phenyl-1pyrazolyl)methanesulfonate Ligand and the Water-Soluble Phosphine 1,3,5-Triaza-7-phosphaadamantane or Related Ligands. Inorg. Chem. 2008, 47, 10158-10168.

(18) Wang, W. Y.; Li, Z.; Chen, J.; Li, C. Crucial Roles of ElectronProton Transport Relay in the Photosystem II-Photocatalytic Hybrid System for Overall Water Splitting. J. Phys. Chem. C. 2017, 121, 2605-2612.

(19) Peng, R.; Li, M.; Li, D. Review Copper(I) halides: A versatile family in coordination chemistry and crystal engineering. Coord. Chem. Rev. 2010, 254, 1-18.

(20) (a) Kang, Y.; Fang, W. H.; Zhang, L.; Zhang, J. A structuredirecting method to prepare semiconductive zeolitic cluster-organic frameworks with $\mathrm{Cu}_{3} \mathrm{I}_{4}$ building units. Chem. Commun. 2015, 51, 8994-8997. (b) Shen, J. J.; Li, X. X.; Yu, T. L.; Wang, F.; Hao, P. F.; $\mathrm{Fu}, \mathrm{Y}$. L. Ultrasensitive Photochromic Iodocuprate(I) Hybrid. Inorg. Chem. 2016, 55, 8271-8273. (c) Shen, J. J.; Song, J.; Yu, T. L.; Fu, Y. L. Structure and photoluminescence of a new $3 \mathrm{D} \quad \mathrm{Cu}_{4} \mathrm{I}_{4}$ hybrid constructed by a flexible acyclic aliphatic diamine with steric effect. Chin. J. Struct. Chem. 2014, 33, 1025-1030. (d) Hao, P. F.; Wang, W. P.; Zhang, L. F.; Shen, J. J.; Fu, Y. L. Metal-dependent electronic and photochromic behaviors of dimethylbenzotriazolium iodometallate hybrids. Inorg. Chem. Front. 2019, 6, 287-292.

(21) (a) Wang, F. R.; Li, Z. Y.; Wei, D. H.; Niu, Y. Y.; Hou, H. W.; $\mathrm{Wu}, \mathrm{B}$. L. The conformational behavior of multivalent tris(imidazolium)cyclophanes in the hybrids with metal (pseudo)halides or polyoxometalates. CrystEngComm 2018, 20, 7184-7194. (b) Li, Y. Y.; Xiao, M.; Wei, D. H.; Niu, Y. Y. Hybrid Supramolecules for Azolium-Linked Cyclophane Immobilization and Conformation Study: Synthesis, Characterization, and Photocatalytic Degradation. ACS Omega 2019, 4, 5137-5146.

(22) Li, L.; Yue, J. M.; Qiao, Y. Z.; Niu, Y. Y.; Hou, H. W. The side chain template effect in viologen on the formation of polypseudorotaxane architecture: six novel metal coordination polymers and their properties. CrystEngComm 2013, 15, 3835-3842.

(23) Yue, Z. C.; Shen, L.-X.; Wu, H. H.; Li, X. H.; Niu, Y. Y. pHdependent assembly of metal-organic hybrid compounds based on octamolybdates and a new flexible multidentate ligand. CrystEngComm 2013, 15, 9938-9948.

(24) Song, L. S.; Wang, H. M.; Niu, Y. Y.; Hou, H. W.; Zhu, Y. The anion exchange reaction of bis(isoquinoline) ionic liquids: selfassembly, crystal structures and thermal properties of ten novel $\mathrm{d}^{10}$ metal ( $\mathrm{Cu}, \mathrm{Ag})$ halide/thiocyanate supramolecular polymers. CrystEngComm 2012, 14, 4927-4938.

(25) Qiao, Y. Z.; Fu, W. Z.; Yue, J. M.; Liu, X. C.; Niu, Y. Y.; Hou, $\mathrm{H}$. W. Role of cooperative templates in the self-assembly process of microporous structures: syntheses and characterization of 12 new silver halide/thiocyanate supramolecular polymers. CrystEngComm 2012, 14, 3241-3249.

(26) Kobayashi, N.; Kamei, Y.; Shichibu, Y.; Konishi, K. Protonation-Induced Chromism of Pyridylethynyl-Appended [core +exo]-Type $\mathrm{Au}_{8}$ Clusters. Resonance-Coupled Electronic Perturbation through П-Conjugated Group. J. Am. Chem. Soc. 2013, 135, $16078-16081$.

(27) Grusenmeyer, T. A.; Chen, J.; Jin, Y.; Nguyen, J.; Rack, J. J.; Schmehl, R. H. pH Control of Intramolecular Energy Transfer and Oxygen Quenching in $\mathrm{Ru}(\mathrm{II})$ Complexes Having Coupled Electronic Excited States. J. Am. Chem. Soc. 2012, 134, 7497-7506.

(28) Li, D.; Song, J.; Yin, P. C.; Simotwo, S.; Bassler, A. J.; Aung, Y. Y.; Roberts, J. E.; Hardcastle, K. I.; Hill, C. L.; Liu, T. B. InorganicOrganic Hybrid Vesicles with Counterion- and $\mathrm{pH}$-Controlled Fluorescent Properties. J. Am. Chem. Soc. 2011, 133, 14010-14016. 
(29) Moore, J. D.; Lord, R. D.; Cisneros, G. A.; Allen, M. J. Concentration-Independent $\mathrm{pH}$ Detection with a Luminescent Dimetallic Eu(III)-Based Probe. J. Am. Chem Soc. 2012, 134, 17372-17375.

(30) Zhao, N.; Sun, F. X.; Zhang, S. X.; He, H. M.; Liu, J.; Li, Q.; Zhu, G. S. Deprotonation-Triggered Stokes Shift Fluorescence of an Unexpected Basic-Stable Metal-Organic Framework. Inorg. Chem. 2015, 54, 65-68.

(31) Faraz, M.; Ambreen, A.; FariaK, K. N.; Neeraj, K.; Ram, P.; Ishan, B.; Rishikesh, P. Polyindole/cadmium sulphide nanocomposite based turn-on, multi-ion fluorescence sensor for detection of $\mathrm{Cr}^{3+}$, $\mathrm{Fe}^{3+}$ and $\mathrm{Sn}^{2+}$ ions. Sens. Actuators, B. 2018, 269, 195-202.

(32) (a) Li, N.-Y.; Liu, D.; et al. Covalent switching, involving divinylbenzene ligands within 3D coordination polymers, indicated by changes in fluorescence. Chem. Commun. 2018, 54, 5831-5834. (b) Lin, S. L.; Hao, P. F.; Shen, J. J.; Fu, Y. L. Hierarchically responsive and photochromic imidazopyridazinium iodoargentate hybrid materials. Dyes Pigm. 2018, 159, 457-463. (c) Liu, Y.; Liu, S. L.; Wang, Y. G. Highly Sensitive Acidic pH Fluorescent Probe Based on A Boradiaza-indacene Derivative. Chem. Res. Chin. Univ. 2010, 26, 249-251.

(33) (a) Adhikari, B.; Palui, G.; Banerjee, A. Self-assembling tripeptide based hydrogels and their use in removal of dyes from waste-water. Soft Matter. 2009, 5, 3452-3460. (b) Zhou, X.; Liu, D.; Lang, F. F.; Ren, Z. G.; Lang, J. P. Two 2D Zinc(II) Coordination Polymers and Their Orange IV Composites: Preparation, Structures, and Photocurrent Responses. Cryst. Growth Des. 2019, 19, 211-218.

(34) Yang, S. F.; Liu, Z. T.; Cai, Z. X.; Luo, H. W.; Qi, P. L.; Zhang, G. X.; Zhang, D. Q. Conjugated Donor-Acceptor Polymers Entailing Pechmann Dye-Derived Acceptor with Siloxane-Terminated Side Chains Exhibiting Balanced Ambipolar Semiconducting Behavior. Macromolecules 2016, 49, 5857-5865.

(35) Qiao, Y. R.; Hao, P. F.; Fu, Y. L. Symmetrically Related Construction and Optical Properties of Two Noncentrosymmetric 3D Iodides of $\mathrm{d}^{10}$ Cation $\left(\mathrm{Cu}^{+}, \mathrm{Ag}^{+}\right)$Based on the N-Benzylpyridinium and Its Supramolecular Interactions. Inorg. Chem. 2015, 54, 87058710 .

(36) (a) Zhu, H. Y.; Jiang, R.; Xiao, L. Adsorption of an anionic azo dye by chitosan $/$ kaolin $/ \gamma-\mathrm{Fe}_{2} \mathrm{O}_{3}$ composites. Appl. Clay Sci. 2010, 48, 522-526. (b) He, H. M.; Song, Y.; Sun, F. X.; Zhao, N.; Zhu, G. S. Sorption Properties and Nitroaromatic Explosives Sensing Based on Two Isostructural Metal-Organic Frameworks. Cryst. Growth Des. 2015, 15, 2033-2038.

(37) Jin, J.; Yang, G. P.; Liu, Y. C.; Cheng, S.; Liu, J.; Wu, D.; Wang, Y. Y. Two Series of Microporous Lanthanide-Organic Frameworks with Different Secondary Building Units and Exposed Lewis Base Active Sites: Sensing, Dye Adsorption, and Magnetic Properties. Inorg. Chem. 2019, 58, 339-348.

(38) Kortüm, G.; Braun, W.; Herzog, G. Prinzip und Meßmethodik der diffusen Reflexionsspektroskopie. Angew. Chem. 1963, 75, 653661.

(39) (a) Dai, M.; Su, X. R.; Wang, X.; Wu, B.; Ren, Z. G.; Zhou, X.; Lang, J. P. Three Zinc(II) Coordination Polymers Based on Tetrakis(4-pyridyl)cyclobutane and Naphthalenedicarboxylate Linkers: Solvothermal Syntheses, Structures, and Photocatalytic Properties. Cryst. Growth Des. 2014, 14, 240-248. (b) Feng, X.; Xu, C.; Wang, Z. Q.; Tang, S. F.; Fu, W. J.; Ji, B. M.; Wang, L. Y. Aerobic oxidation of alcohols and the synthesis of benzoxazoles catalyzed by a cuprocupric coordination polymer $\left(\mathrm{Cu}^{+}-\mathrm{CP}\right)$ Assisted by TEMPO. Inorg. Chem. 2015, 54, 2088-2090.

(40) (a) Li, N. Y.; Liu, D.; Ren, Z. G.; Lollar, C.; Lang, J. P.; Zhou, H. C. Controllable Fluorescence Switching of a Coordination Chain Based on the Photoinduced Single-Crystal-to-Single-Crystal Reversible Transformation of a syn-[2.2] Metacyclophane. Inorg. Chem. 2018, 57, 849-856. (b) Wang, H. Y.; Hou, L. L.; Li, C.; Zhang, D. D.; Ma, P. T.; Wang, J. P.; Niu, J. Y. Synthesis, structure, and photocatalytic hydrogen evolution of a trimeric $\mathrm{Nb} / \mathrm{W}$ addendum cluster. RSC Adv. 2017, 7, 36416-36420. (c) Wang, Y.; Ma, P. T.; Niu, J. Y. Organic-inorganic hybrid rare earth complexes based on polymolybdates with intrinsic photosensitive properties. Dalton Trans. 2015, 44, 4679-4682. (d) You, J. C.; Wu, H.; Du, L. M.; Fu, Y. L. Cloud-point extraction and fluorospectrophotometric determination of rhodamine B in water samples. Asian J. Chem. 2014, 26, 50215025.

(41) (a) Liu, G. N.; Zhang, X.; Wang, H. M.; Xu, H.; Wang, Z. H.; Meng, X. L.; Dong, Y. N.; Zhao, R. Y.; Li, C. C. Do alkyl groups on aromatic or aliphatic structure directing agents affect water stabilities and properties of hybrid iodoargentates? Dalton Trans. 2017, 46, 12474-12486. (b) Hu, T. T.; Liu, T. T.; Zhang, Z. H.; Wang, Y.; Yang, Y. G.; Young, D. J.; Hu, C. J.; Lang, J. P. Precise control of chirality transfer by adjusting the alkyl substituents of guests. Dyes Pigm. 2019, 160, 692-699. (c) Bisht, K. K.; Parmar, B.; Rachuri, Y.; Kathalikattil, A. C.; Suresh, E. Progress in the synthetic and functional aspects of chiral metal-organic frameworks. CrystEngComm 2015, 17, 5341-5356. (d) Hao, P. F.; Qiao, Y. R.; Yu, T. L.; Shen, J. J.; Liu, F.; $\mathrm{Fu}, \mathrm{Y}$. L. Three iodocuprate hybrids symmetrically modulated by positional isomers and the chiral conformation of N-benzylmethylpyridinium. RSC Adv. 2016, 6, 53566. (e) Hao, P. F.; Qiao, Y. R.; Yu, T. L.; Shen, J. J.; Dai, D. T.; Fu, Y. L. Spontaneous chiral resolution and hierarchical directing effects of two-winged propellerlike SDAs on the construction of noncentrosymmetric iodoargentates/iodocuprates. RSC Adv. 2016, 6, 87628-87636.

(42) (a) Zhang, L.; Jin, Q.; Liu, M. Enantioselective Recognition by Chiral Supramolecular Gels. Chem. Asian J. 2016, 11, 2642-2649. (b) Zhang, Z. Y.; Deng, Z. P.; Huo, L. H.; Zhao, H.; Gao, S. Inorganic anion induced supramolecular architectures of flexible unsymmetrical bis(pyridyl) ionic salts mediated by various non-covalent interactions. CrystEngComm 2013, 15, 5261-5274.

(43) Zhou, Y. M.; Zhang, J. L.; Zhang, L.; Zhang, Q. Y.; Ma, T. S.; Niu, J. Y. A rhodamine-based fluorescent enhancement chemosensor for the detection of $\mathrm{Cr}^{3+}$ in aqueous media. Dyes Pigm. 2013, 97, $148-154$.

(44) Li, H. H.; Han, Y. B.; Shao, Z. C.; Li, N.; Huang, C.; Hou, H. W. Water-stable Eu-MOF fluorescent sensors for trivalent metal ions and nitrobenzene. Dalton Trans. 2017, 46, 12201-12208.

(45) (a) Gao, Y. L.; Shu, J. M.; Zhang, C.; Zhang, X.; Chen, H. Y.; Yao, K. J. A fluorescence on-off sensor for $\mathrm{Cu}^{2+}$ and its resultant complex as an off-on sensor for $\mathrm{Cr}^{3+}$ in aqueous media. RSC $A d v$. 2015, 5, 74629. (b) Andrea, B.-B.; Laura, C.; Anam, C.; Salvador, G.; Ramon, M. M.; Felix, S. Off-on BODIPY-based chemo sensors for selective detection of $\mathrm{Al}^{3+}$ and $\mathrm{Cr}^{3+}$ versus $\mathrm{Fe}^{3+}$ in aqueous media. RSC Adv. 2014, 4, 8962. (c) Dai, Y. P.; Liu, X. Y.; Wang, P.; Fu, J. X.; Yao, K.; Xu, K. X. A new fluorescent probe based on quinoline for detection of $\mathrm{Al}^{3+}$ and $\mathrm{Fe}^{3+}$ with "off-on-off" response in aqueous solution. RSC Adv. 2016, 6, 99933-99939. (d) Lohar, S.; Arnab, B.; Animesh, S.; Avishek, B.; Subhra, K. M.; Debasis, D. A rhodaminenaphthalene conjugate as a FRET based sensor for $\mathrm{Cr}^{3+}$ and $\mathrm{Fe}^{3+}$ with cell staining application. Anal. Methods 2013, 5, 442. 